\title{
Characterization of Quinone Outside Inhibitor Fungicide Resistance in Cercospora sojina and Development of Diagnostic Tools for its Identification
}

F. Zeng, Department of Plant Biology, University of Illinois, Urbana 61801, and State Key Laboratory of Crop Biology, Shandong Agricultural University, Tai'an, Shandong, China; E. Arnao, Department of Plant, Soil, and Agricultural Systems, Southern Illinois University, Carbondale 62901; G. Zhang, Department of Crop Sciences, University of Illinois; G. Olaya, Syngenta Crop Protection, Vero Beach, FL 32967; J. Wullschleger and H. Sierotzki, Syngenta Crop Protection, Stein, Switzerland; R. Ming, Department of Plant Biology, University of Illinois; B. H. Bluhm, Department of Plant Pathology, University of Arkansas, Fayetteville 72701; J. P. Bond and A. M. Fakhoury, Department of Plant, Soil, and Agricultural Systems, Southern Illinois University; and C. A. Bradley, Department of Crop Sciences, University of Illinois

\begin{abstract}
Zeng, F., Arnao, E., Zhang, G., Olaya, G., Wullschleger, J., Sierotzki, H., Ming, R., Bluhm, B. H., Bond, J. P., Fakhoury, A. M., and Bradley, C. A. 2015. Characterization of quinone outside inhibitor fungicide resistance in Cercospora sojina and development of diagnostic tools for its identification. Plant Dis. 99:544-550

Frogeye leaf spot of soybean, caused by the fungus Cercospora sojina, reduces soybean yields in most of the top-producing countries around the world. Control strategies for frogeye leaf spot can rely heavily on quinone outside inhibitor (QoI) fungicides. In 2010, QoI fungicide-resistant C. sojina isolates were identified in Tennessee for the first time. As the target of QoI fungicides, the cytochrome $\mathrm{b}$ gene present in fungal mitochondria has played a key role in the development of resistance to this fungicide class. The cytochrome $\mathrm{b}$ genes from three QoI-sensitive and three QoI-resistant $C$. sojina isolates were cloned and sequenced. The complete coding sequence of the cytochrome $b$ gene was identified

and found to encode 396 amino acids. The QoI-resistant $C$. sojina isolates contained the G143A mutation in the cytochrome $b$ gene, a guanidine to cytosine transversion at the second position in codon 143 that causes an amino acid substitution of alanine for glycine. C. sojina-specific polymerase chain reaction primer sets and TaqMan probes were developed to efficiently discriminate QoI-resistant and -sensitive isolates. The molecular basis of QoI fungicide resistance in field isolates of $C$. sojina was identified as the G143A mutation, and specific molecular approaches were developed to discriminate and to track QoI-resistant and -sensitive isolates of $C$. sojina.
\end{abstract}

Yields of soybean grown in the top-producing countries in the world can be negatively affected by Cercospora sojina, the causal agent of frogeye leaf spot (38). Estimated annual soybean yield reductions caused by frogeye leaf spot in the United States ranged between 19,568 and 345,148 metric tons from 1996 to 2009 (22,37). Practices recommended for management of frogeye leaf spot include planting resistant cultivars, planting pathogen-free seed, rotating to nonhost crops, and applying foliar fungicides (26). Fungicides in the quinone outside inhibitor (QoI) group have been shown to provide good efficacy against frogeye leaf spot in field research trials $(15,24)$. Despite their typical high level of efficacy in controlling the disease, $C$. sojina isolates collected from a soybean field in Lauderdale County, TN, were found to be highly resistant to QoI fungicides in 2010 (40). Because QoI fungicides have a high risk of target fungi developing resistance to them, with over 30 species across 20 genera reported to show field resistance (17), and a high level of genetic diversity exists in $C$. sojina, with some populations likely undergoing sexual reproduction $(10,20)$, the finding of QoI-resistant $C$. sojina isolates was not unexpected.

QoI fungicides inhibit mitochondrial respiration in fungi by binding to the quinol oxidation site. The interaction of the fungicide with the target blocks electron transfer between cytochrome $\mathrm{b}$ and cytochrome $\mathrm{c} 1$ and leads to a lack of ATP production (4). Three different point mutations in the cytochrome $b$ gene were found to be associated with QoI fungicide resistance in fungi. The mutations include (i) a change from glycine to alanine at codon 143 (G143A), (ii) a change from phenylalanine to leucine at codon 129 (F129L), and (iii) a change from glycine to arginine at

Corresponding author: C. A. Bradley; E-mail: carlbrad@illinois.edu

F. Zeng and E. Arnao share first authorship.

Accepted for publication 19 October 2014.

http://dx.doi.org/10.1094/PDIS-05-14-0460-RE

(C) 2015 The American Phytopathological Society codon 137 (G137R) (16). The effect of the different mutations on resistance to QoI fungicides varies. G143A is the most commonly observed mutation in QoI-resistant plant-pathogenic fungi, and isolates harboring this mutation show the highest level of resistance (16).

Analysis of the cytochrome $b$ gene has revealed the presence of introns in several plant-pathogenic fungi. In some plant-pathogenic fungi, an intron that begins directly after codon 143 will lead to the lethal deficiency of cytochrome $b$ and reduce the likelihood of the G143A mutation becoming established $(19,32,35)$.

Monitoring field populations of plant-pathogenic fungi for the presence of QoI-resistant isolates is needed to study evolution of resistance and to determine the potential efficacy of QoI fungicides in production fields. The objectives of this study were to identify the mutation responsible for QoI resistance in C. sojina, determine the presence of an intron located directly downstream of codon 143, and develop tools to efficiently detect QoI-resistant and -sensitive isolates of $C$. sojina.

\section{Materials and Methods}

C. sojina isolates and DNA isolation. $C$. sojina isolates that were used in this research are listed in Table 1 . They included isolates that were sensitive to QoI fungicides, one of which (S9) was used as part of a larger collection to establish the baseline sensitivity of $C$. sojina to QoI fungicides (41). Thirteen $C$. sojina isolates were collected from a soybean field in Lauderdale County, TN, where frogeye leaf spot was not controlled with applications of QoI fungicides. These 13 isolates had values of effective concentrations of QoI fungicides that inhibited conidial germination by $50 \%\left(\mathrm{EC}_{50}\right)$ at least 100 -fold greater than $\mathrm{EC}_{50}$ values reported for $C$. sojina baseline isolates (40). In all, 67 of the isolates were collected from soybean production fields in Arkansas and 114 isolates were collected from two fields in Illinois. The $\mathrm{EC}_{50}$ values of all isolates used in this study were previously determined using methods described in Zhang et al. (41). DNA was extracted using FastDNA kits (Qbiogene Inc., Carlsbad, CA), as described previously (10).

Cytochrome b gene cloning and sequence analysis. $C$. sojina isolate S9, originally collected from a soybean field in Georgia by 
Dr. D. V. Phillips (University of Georgia, Griffin) and used as one of several QoI-sensitive baseline isolates in a previous study (41), was used for nuclear and mitochondrial genome sequencing at the University of Illinois W. M. Keck Center for Comparative and Functional Genomics (Urbana). The complete coding sequence of the cytochrome $\mathrm{b}$ gene was identified based on publicly available sequences from other fungal species (C. kikuchii GenBank accession number AB231863, C. beticola GenBank accession number EF176921,

Table 1. Cercospora sojina isolates used in this research

\begin{tabular}{|c|c|c|}
\hline Isolate designations ${ }^{a}$ & Origin & $\begin{array}{c}\text { Sensitivity to } \\
\text { quinone outside } \\
\text { inhibitor fungicides }\end{array}$ \\
\hline S9 & $\begin{array}{l}\text { Georgia (from baseline } \\
\text { isolate collection) (41) }\end{array}$ & Sensitive \\
\hline SYN-05-61 & Indiana & Sensitive \\
\hline SYN-05-62 & Indiana & Sensitive \\
\hline UIUC-1 & Gallatin County, IL & Sensitive \\
\hline UIUC-2 & Lauderdale County, TN & Sensitive \\
\hline UIUC-3 & Gibson County, TN & Sensitive \\
\hline UIUC-4 & Caldwell County, KY & Sensitive \\
\hline UIUC-5 to UIUC-17 & Lauderdale County, TN & Resistant \\
\hline UARK-1 to UARK-13 & Crawford County, AR & Sensitive \\
\hline UARK-14 to UARK-32 & Cross County, AR & Sensitive \\
\hline UARK-33 to UARK-67 & Phillips County, AR & Resistant \\
\hline SIU-1 to SIU-23 & Alexander County, IL & Sensitive \\
\hline SIU-24 to SIU-68 & Alexander County, IL & Resistant \\
\hline SIU-69 to SIU-87 & Gallatin County, IL & Sensitive \\
\hline SIU-88 to SIU-114 & Gallatin County, IL & Resistant \\
\hline
\end{tabular}

a Isolates with designations SYN, UIUC, UARK, and SIU are maintained by Syngenta Crop Protection, the University of Illinois, the University of Arkansas, and Southern Illinois University, respectively.
Mycosphaerella graminicola GenBank accession number AY247413, and Rhynchosporium secalis GenBank accession number FJ346339). Gene sequences were blasted against previously reported nucleotide sequences of $C$. beticola and $C$. kikuchii to identify the gene structure, which was confirmed by alignment with $C$. beticola mRNA and homolog protein sequence in the National Center for Biotechnology Information (NCBI) $\mathrm{Nr}$ protein sequence database (http://www.ncbi. nlm.nih.gov/). Open reading frames (ORF) were predicted using genetic code 4 in the ORF Finder Tool (http://www.ncbi.nlm.nih.gov/ projects/gorf/).

Sequencing of the cytochrome $b$ gene in QoI-sensitive and -resistant $C$. sojina isolates. The cytochrome b gene was sequenced in three QoI-sensitive isolates (S9, SYN-05-61, and SYN-05-62) and three QoI-resistant isolates (UIUC-5, UIUC-9, and UIUC-15) (Table 1). Vector NTI10 (Life Technologies, Grand Island, NY) was used to design primers to amplify the region of the cytochrome $b$ gene that contains previously reported mutations that confer resistance to QoI fungicides (Table 2). Polymerase chain reaction (PCR) was carried out using an iCycler PCR thermal cycler (Bio-Rad, Hercules, CA) or GeneAmp PCR Systems 9700 (Applied Biosystems, Foster City, CA) in 25- $\mu 1$ reaction volumes containing $0.625 \mathrm{U}$ of GoTaq Hot Start Polymerase, $1 \times$ Green GoTaq Flexi Buffer, $2 \mathrm{mM} \mathrm{MgCl} 2,0.2 \mathrm{mM}$ each dNTP (all supplied by the manufacturer Promega Corp., Madison, WI), $0.2 \mu \mathrm{M}$ each primer, and $25 \mathrm{ng}$ of template. In the first step, DNA was denatured at $95^{\circ} \mathrm{C}$ for $2 \mathrm{~min}$ and was then amplified in 30 cycles with denaturation at $95^{\circ} \mathrm{C}$ for $30 \mathrm{~s}$, annealing at $50^{\circ} \mathrm{C}$ for $30 \mathrm{~s}$, and extension at $72^{\circ} \mathrm{C}$ for $1 \mathrm{~min}$ (or $4 \mathrm{~min}$ for amplicons longer than $600 \mathrm{bp}$ ). A final extension at $72{ }^{\circ} \mathrm{C}$ for $5 \mathrm{~min}$ completed the PCR. The combination of primer pairs produced the amplicons CERC cytb 1f/CERC cytb 1r of 143 bp spanning codon 129, CERC cytb 1f/CERC cytb $2 \mathrm{r}$ of approximately 1,400 bp spanning codons 129 and 143, CERC cytb 2f/CERC cytb 3r of approximately $1,500 \mathrm{bp}$ spanning codon 143, and Mut4-F/Mut4-R of approximately $380 \mathrm{bp}$ spanning codons 129, 137, and 143 (Table 2).

Table 2. Primers used to screen for mutations in the cytochrome b gene of Cercospora sojina

\begin{tabular}{llclc}
\hline Primer number & Direction & Product size $(\mathbf{b p})$ & \multicolumn{1}{c}{ Sequence $\left(\mathbf{5}^{\prime} \mathbf{- 3} \mathbf{3}^{\prime}\right)$} & Other information \\
\hline CERC cytb 1F & Forward & 143 & TTACACGTAGGAAGAGGTCTATACTATG & Spanning area of F129 L \\
CERC cytb 1R & Reverse & & CATAAAGACATTTGTCCGTAAGG & mutation \\
CERC cytb 1F & Forward & 1,400 & TTACACGTAGGAAGAGGTCTATACTATG & Spanning area of F129 L, G137, \\
CERC cytb 2R & Reverse & & CTAATGCAGCTAATACGAAAGGTAA & S143A mutations \\
CERC cytb 2F & Forward & 1,500 & ATGTTTTACCTTACGGACAAATGTC & Spanning area of G143A \\
CERC cytb 3R & Reverse & \multirow{2}{*}{380} & CTGCACTATCATGTAAAGCAATTAAGT & mutation \\
Mut4-F & Forward & & GATTCACCTCAGCCTTCAAA & Spanning area of F129 L, G137R, \\
Mut4-R & Reverse & & CTCAACTATGTCCTGTCCTACTCA & and G143A mutations \\
\hline
\end{tabular}

Table 3. Polymerase chain reaction (PCR) primers and probes for detection of the wild type (WT), G143A mutation, and specific introns in the cytochrome b gene in Cercospora sojina

\begin{tabular}{|c|c|c|c|c|}
\hline Name & Direction & Product size (bp) & Sequence $\left(5^{\prime}-3^{\prime}\right)$ & Other information \\
\hline $\mathrm{Cs}-1 \mathrm{~F}$ & Forward & 207 & TAATACAGCTTCAGCATTTTTCTTCT & G143A-specific primer \\
\hline Cs1R & Reverse & & CTCATTAAATTAGTAATAACTGTGGCAG & \\
\hline Cs-1F & Forward & 207 & TAATACAGCTTCAGCATTTTTCTTCT & G143A-specific primer \\
\hline Cs-1R-2 & Reverse & & CTCATTAAATTAGTAATAACTGTGGCCG & (optimized) \\
\hline $\mathrm{Cs}-1 \mathrm{~F}$ & Forward & 207 & TAATACAGCTTCAGCATTTTTCTTCT & G143A-specific primer \\
\hline Cs-1R-3 & Reverse & & CTCATTAAATTAGTAATAACTGTGGTCG & \\
\hline $\mathrm{Cs}-1 \mathrm{~F}$ & Forward & 244 & TAATACAGCTTCAGCATTTTTCTTCT & Codon 143 intron \\
\hline Cs-3R & Reverse & & AAACTCAACTATGTCCTGTCCTACTCA & \\
\hline Cs-1F & Forward & 1,553 & TAATACAGCTTCAGCATTTTTCTTCT & Codon 169 intron \\
\hline Cs-4R & Reverse & & CGAAAGGTAATACGAAATGTAATGC & \\
\hline $\mathrm{Cs}-2 \mathrm{~F}$ & Forward & 359 & GGTTCACTATTAGGATTTTGTCTTGTA & WT-specific primer \\
\hline Cs-5R-1 & Reverse & & CTCATTAAATTAGTAATAACTGTGGCGC & \\
\hline $\mathrm{Cs}-2 \mathrm{~F}$ & Forward & 359 & GGTTCACTATTAGGATTTTGTCTTGTA & WT-specific primer \\
\hline Cs-5R-2 & Reverse & & CTCATTAAATTAGTAATAACTGTGGCCC & (optimized) \\
\hline Cytb-F & Forward & 34 & GGGTTATGTTTTACCTTACGGACAAATG & Specific primer for \\
\hline Cytb-R & Reverse & & GTCCTACTCATGGTATTGCACTCA & real-time PCR \\
\hline Probe-VIC & $\ldots$ & $\ldots$ & ACTGTGGCAGCTCATAA & Specific probes for \\
\hline Probe-FAM & $\ldots$ & $\ldots$ & ACTGTGGCACCTCATAA & real-time PCR \\
\hline
\end{tabular}


PCR clean-up was performed by using the NucleoSpin Extract II Kit (Macherey-Nagel, Düren, Germany). The purified PCR products were directly sequenced using the BigDye Terminator Cycle Sequencing Kit (v3.1; Life Technologies, Grand Island, NY) following the manufacturer's instructions. Cycle sequencing was carried out on a GeneAmp PCR Systems 9700 using the same forward and reverse primers as for amplification of the cytochrome $b$ gene. The reaction products were cleaned by a spin column purification (DyeEx 2.0 Spin Kit; Qiagen, Hiden, Germany). Electrophoresis was accomplished on the ABI Prism 3130 Genetic Analyzer (Life Technologies). Sequencing analysis was done with the DNASTAR Lasergene 8 software (DNASTAR, Madison, WI).

Development of PCR primers and probes to discriminate QoIresistant and -sensitive $C$. sojina isolates and to detect cytochrome b introns. A series of primers were designed based on the identified point mutation G143A in the $C$. sojina cytochrome $\mathrm{b}$ gene to screen optimized specific probes for molecular diagnosis of QoI-resistant and -sensitive isolates as well as presence of introns.
Information regarding primers and probes are shown in Table 3 and Figure 1.

Primers for detection of QoI resistance were designed with a mismatch on the penultimate nucleotide of the $3^{\prime}$ end of the forward primer, in which the ultimate nucleotide was at the point mutation position of codon 143 of the cytochrome $b$ gene $(11,31)$. The primer set used to amplify a 207-bp amplicon in QoI-resistant strains was the forward primer, Cs-1F, and the reverse primer, Cs-1R-2. Cs-1R-2 harbored a mismatch of $\mathrm{C}$ instead of $\mathrm{A}$ at nucleotide 434. Therefore, the primer set for detection of QoI resistance, Cs-1F/Cs-1R-2, resulted in a single nucleotide mismatch on resistant strains and a double nucleotide mismatch on sensitive strains, and vice versa for the primer set for detection of QoI-sensitive strains, Cs-2F/Cs-5R-2.

Molecular discrimination between QoI-sensitive and -resistant isolates was tested using a gradient of PCR annealing temperatures (50 to $65^{\circ} \mathrm{C}$ ). Allele-specific PCR assays were carried out in $25-\mu 1$ reaction volumes with GoTaq Green Master Mix (Promega Corp.), $0.1 \mu \mathrm{M}$ each primer, and $5 \mathrm{ng}$ of template. The resulting PCR products

A ATGAGAATATTTAAAAGTCACCCTTTATTAAGTTTAGTTAATGGTTATTTAGTTGATTCGCCTCAGCCTTCAAATATTAGTTACT TGTGAAACTTTGGTTCACTATTAGGATTTTGTCTTGTAATACAAATCGTAACAGGAGTTACTTTGGCTATGCACTACAATCCTA GCGTACTTGAAGCATTTAATTCAGTAGAACATATTATGAGAGACGTAAATAACGGATGATTAATACGTTACTTACACTCTAATA CAGCTTCAGCATTTTTCTTCTTAGTATACTTACACGTAGGAAGAGGTCTATACTATGGTTCTTACAAAGCACCTAGAACATTG $\mathrm{Cs}-\mathrm{F} \rightarrow$

GTATGAACTATAGGTACTATTATATTTGTTTTAATGATGGCTACTGCATTTTTGGGTTATGTTTTACCTTACGGACAAATGTCTTT ATGAG $\boldsymbol{G} / \boldsymbol{C}$ TGCCACAGTTATTACTAATTTAATGAGTGCAATACCATGAGTAGGACAGGACATAGTTGAGTTTTTATGAGGAGG $\leftarrow$ Cs-1R/Cs-5R $\leftarrow$ Cs-3R

TTTATGTCGCATAGCGAAAGATGGACCACATTACGGTGACGTAGTGTTAAAAATTCTGCTTAATGCTGGAAAATCTCCCAATT TAGGATTTGCATACGTCTTTTTCTTGATTTTAATATCAATTTTTTGCGTAAAAATTGCAATGACATGGAGACAATCAGCAGGGG TGAAAAGTATACATACTTCACAAGCCTCTCAGAGACTACATGCAGAAGATCTCACATATGCTTATTTAGTTGGTTTATTTGAAG GTGATGGATATTTTTCTATTTCAAAAAAAGGTAAATATCTAACCTACGAATTAGGTATTGAATTGTCGATTAAAGATGTGCAATT GATTTATAAAGTAAAATCTTTATTAGGTGTAGGTGTGGTAAGTTTTAGAAAAAGAAAACAAATAGTTCTACATAAATCTGAAAT AGTTTTGTTGGATATGGTAGCTCTAAAAATAAGGGATAAAAATCACTTGAAAAAGTTTATAATAACCTATTTTCGATAAATATC CTATGTTTTCTAACAAACAGTATGATTATTTAAGATTTAAAAATGGTTTACTTTTCAGATATTATATATTCAAAAGATTTGCCTGA ATACATTAGAAGTAATGTGGCTTTAAATACTATAGAATCTATAATTAATACTAGTTATTTTTCTGCCTGATTAGTAGGATTTATAG AAGCTGAAGGCTGTTTTAGCGTATATAAGTTAGAAAATAATAAGGACTATTTAGTAGCAAGTTTCGATATATCTCAAACACACG GAGAAATTATCATATCCGCTATTCGTAAATATTTATCTTTTACCACTGCGATATACGTAGATAAAAATGATTGTTCAAAGTTAAA AGTTACAAGTGTAAGATCAATAGAAAATATTATCAAGTTTATACATAAAGCACCTGTAAAATTTGGTTGGGAAATAAAAAGTT ACAATACTTATTATGAATAAAACAATTGCGTACAATACCTAGGTATTATAAAAACATAAAAATACCTTCCAATTATTAAATAATC ACGAGATCAAGATATAGTCCGATCAATGAAGAAATTCATTGCGTATAGTAAGAGTATTTAAACAACTTAGCTGTTGTATTAAAT ATGTTAACTATCAACATAAATGCTCTGTAAACAATGCCACATTAAATAGATTTTTTGCATTACATTTCGTATTACCTTTCGTATTA $\leftarrow$ Cs-4R

GCTGCACTAGCTTTAATGCACCTAATTGCTTTACATGATAGTGCAGGTTCAGGTAATCCTTTAGGAGTTTCTGGTAATTATGAC AGAATTCCTTTTGCTCCATACTTTATATTTAAAGATTTAATAACTATATTTTTATTTATAATAGTATTATCAGTGTTTGTTTTCTTGA TGCCTAACGTTTTAGGTGATAGTGAAAATTACGTTGTGGCTAATCCAATGCAAACACCTCCTGCTATAGTACCAGAGTGATATT TATTACCCTTCTACGCTATATTAAGATCTATACCTAACAAATTATTAGGTGTTATTGCTATGTTCTCTGCTATATTAATAATACTAA CTATGCCTTTTACAGACTTAGGTAGAAGTAGAGGATTACAGTTTAGGCCTTTAAGTAAAATAGCATTCTACATATTTGTAGCAA ATTTCTTATTATTGATGCAATTAGGTGCTAAACACGTTGAATCACCATTCATAGAATTTGGTCAACTAAGTACGGTTTTATACTT TTCACATTTCTTGATAATAGTTCCATTAGTTAGTTTATTAGAGAATAGTTTAATTGAATTACACCTTAGTAAGACCCATGTGAAT ATCCAAAAGTCTTATAATATGAGA

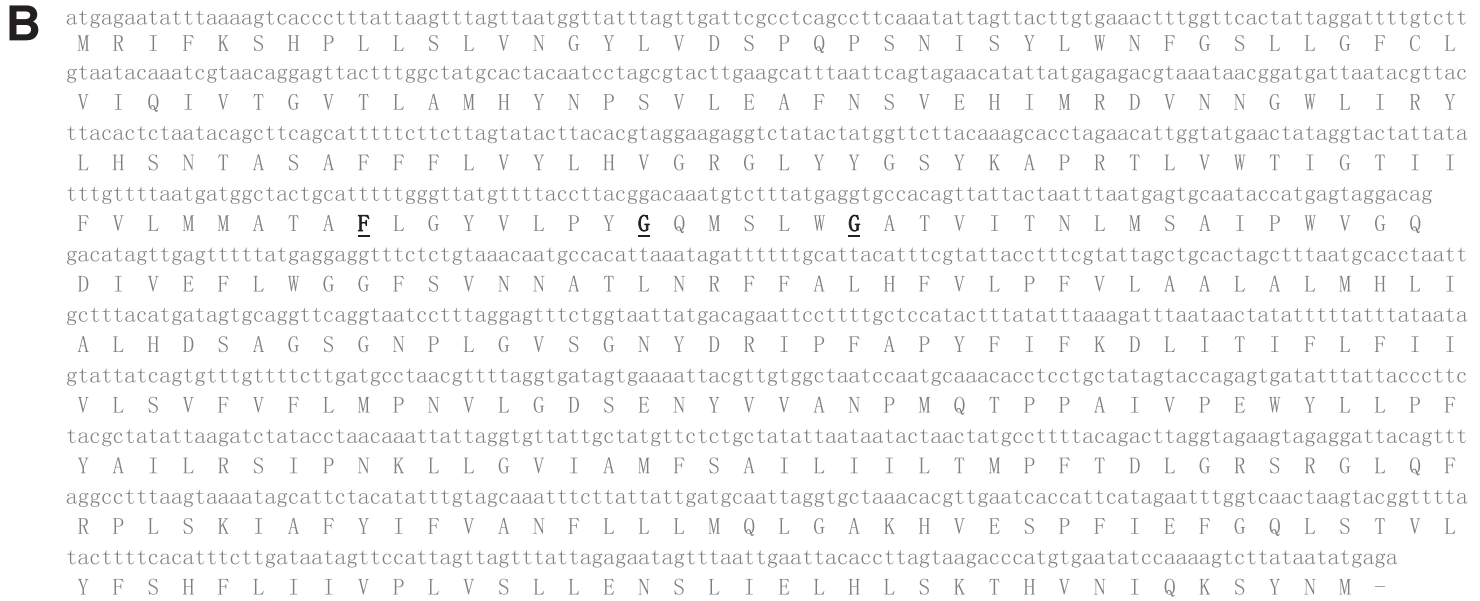

Fig. 1. Complete cytochrome b gene CDS nucleotide and amino acid sequence in Cercospora sojina. A, Cytochrome b gene sequence with two exons and one intron, which is ripping the codon of F169. Shaded nucleotides indicate exons and nonshaded nucleotides indicate the intron. The G143A mutant site is in bold and in larger italics font. Underlines indicate the diagnosis primer locations. B, Cytochrome $b$ gene open reading frame region nucleotide and amino acid sequence. Top line shows nucleotide sequence and bottom line show amino acid sequence. Known codon sites for mutations F129 L, G137A, and G143A are underlined and in bold. 
were visualized and analyzed on $1 \%$ ethidium bromide-stained agarose gels. To assess the sensitivity of each primer set, template DNA isolated from QoI-sensitive isolates and the QoI-resistant isolates was diluted in a $2 \times$ dilution series from $10 \mathrm{ng}$ to $1.2 \mathrm{pg}$.

Primers also were designed to detect the presence of introns in the cytochrome $b$ gene. Combinations of primers were used to detect specifically the introns at codons 143 and 169 (Table 3 ) for all of the UIUC isolates (Table 1). The conditions of the PCR reactions were the same as those listed above.

Development of a single-nucleotide polymorphism TaqMan assay to detect the G143A mutation in $C$. sojina. Primers and probes were designed and supplied by Applied Biosystems. The assay included two specific primers targeting the region flanking the point mutation of $\mathrm{G} 143 \mathrm{~A}$ and two allele-specific probes $(\mathrm{G} / \mathrm{C})$ (Table 3). The discrimination between both alleles was achieved by labeling the allele-sensitive and allele-resistant probes with FAM and VIC at the $5^{\prime}$ end, respectively.

The assays for single-nucleotide polymorphism (SNP) genotyping were carried out using a CFX96 real-time PCR detection system (Bio-Rad) and analyzed with CFX Manager software (version 3.1). PCR amplifications were carried out at $95^{\circ} \mathrm{C}$ for $3 \mathrm{~min}$ followed by 39 cycles at $95^{\circ} \mathrm{C}$ for $15 \mathrm{~s}$ and $62^{\circ} \mathrm{C}$ for $1 \mathrm{~min}$. Amplifications were made in $20 \mu \mathrm{l}$ of reaction, each consisting of $1 \times$ iTaq Universal Probe Supermix (Bio-Rad), $1 \times$ SNP TaqMan assay (Applied Biosystems), and $50 \mathrm{ng}$ of DNA. In each run, one isolate carrying the resistant mutation was used as a positive control.

PCR efficiency was determined using standard curves produced by plotting threshold cycle values against the logarithm of concentration of QoI-sensitive and -resistant isolate DNA serially diluted in 1:10 ratios. Overall, six concentrations were used, starting from a concentration of $80 \mathrm{ng} / \mu \mathrm{l}$. To evaluate the assay sensitivity, mixtures of DNA (total concentration of $30 \mathrm{ng} / \mu \mathrm{l}$ ) from sensitive and resistant isolates were used at ratios of 10:0, 9:1, 7:3, 5:5, 3:7, 1:9, and 0:10. DNA concentrations were measured in a Nanophotometer P-Class (Implen, Westlake Village, CA). Moreover, the specificity of the assay was assessed using DNA extracted from C. kikuchii, Septoria glycines, Macrophomina phaseolina, Fusarium solani, F. oxysporum, F. acuminatum, F. graminearum, Alternaria alternata, Sclerotium rolfsii, and Pythium ultimum.

\section{Results}

Cytochrome b gene cloning and sequence analysis. The complete coding sequence of the $C$. sojina cytochrome b gene was determined by comparing against sequences of cytochrome b gene homologs reported in related fungal species (C. kikuchii, C. beticola, Mycosphaerella graminicola, and $R$. secalis) using the BLAST server in NCBI (http://www.ncbi.nlm.nih.gov/). The full-length gene sequence was 2,307 bp with two exons and one intron, which was ripping the codon F169 (Fig. 1A). This was confirmed by alignment with $C$. beticola mRNA. This sequence was blasted against nucleotide sequences and showed an identity of $97 \%$ in the first exon and 95 and $94 \%$ in the second exon with $C$. beticola and C. kikuchii, respectively. Top BLASTP hits of the deduced 396-amino acid C. sojina cytochrome b sequence (Fig. 1B) included cytochrome $\mathrm{b}$ from Zymoseptoria tritici (E-value $=0.0 ; 93 \%$ identity, $97 \%$ similarity), Phialocephala subalpina (E-value $=0.0 ; 92 \%$ identity, $97 \%$ similarity), $R$. secalis (E-value $=0.0 ; 90 \%$ identity, $96 \%$ similarity), Peltigera membranacea (E-value $=0.0 ; 89 \%$ identity, $96 \%$ similarity), $P$. malacea $($ E-value $=0.0 ; 89 \%$ identity, 96\% similarity), and Venturia inaequalis (E-value $=0.0 ; 89 \%$ identity, $96 \%$ similarity).

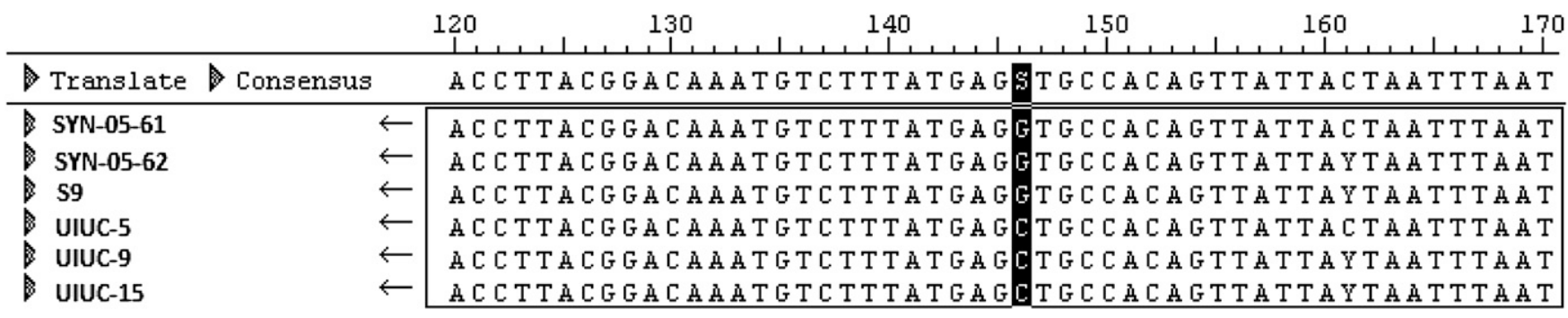

Fig. 2. DNA sequencing investigation for the cytochrome b gene mutation in quinone outside inhibitor (Qol)-resistant and -sensitive Cercospora sojina isolates. Qol-sensitive isolates SYN 05-61, SYN 05-62, and S9 have G at the second position of the codon of amino acid 143, whereas Qol-resistant isolates UIUC-5, UIUC-9, and UIUC-15 have C.

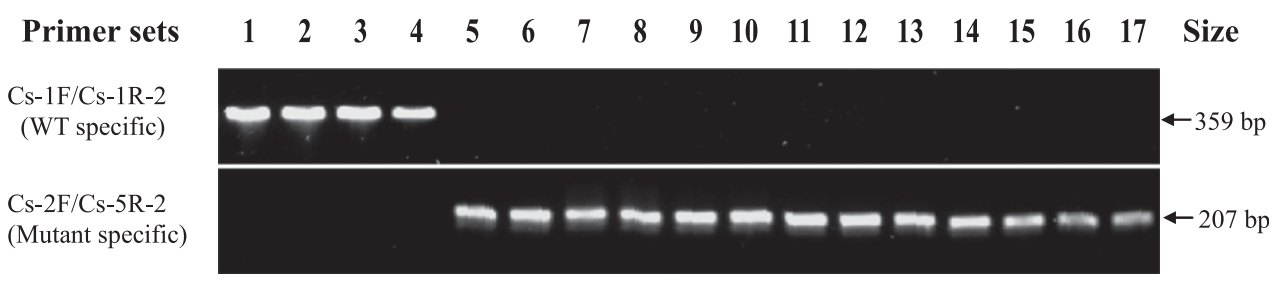

B

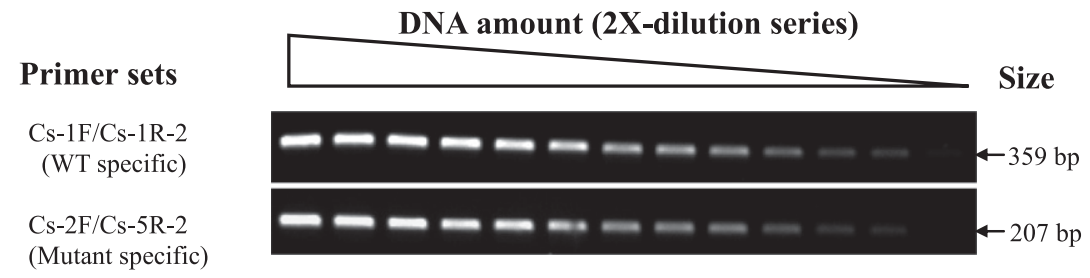

Fig. 3. Molecular diagnosis of quinone outside inhibitor (Qol)-resistant and -sensitive Cercospora sojina isolates by developed specific primer sets. A, Allele-specific polymerase chain reaction (PCR) to discriminate between Qol-resistant and -sensitive C. sojina isolates using optimized primer sets. Isolates 1 to 4 are Qol-sensitive and isolates 5 to 17 are Qol-resistant. WT = wild type. B, Sensitivity of Qol-sensitive and -resistant specific primer sets. Template DNA of Qol-sensitive isolate number 2 and Qol-resistant isolate number 15 was diluted in a $2 \times$ dilution series from $10 \mathrm{ng}$ to $1.2 \mathrm{pg}$ for PCR reactions. Both primers can detect a minimum of approximately 2.4 pg of DNA as template in PCR reactions. 
Sequencing of the cytochrome b gene from QoI-sensitive and -resistant $C$. sojina isolates. Sequence comparison of the cytochrome b gene fragment of QoI-sensitive and QoI-resistant strains revealed a guanidine to cytosine transversion at the second position in codon 143 leading to an amino acid change from glycine (GGT) to alanine (GCT) in resistant isolates (Fig. 2).

Molecular detection of the G143A mutation site to discriminate QoI-resistant and -sensitive isolates using conventional PCR. Several primer pairs were designed to differentiate QoI-sensitive and -resistant isolates based on the G143A point mutation. The optimized PCR program for this was as follows. In the first cycle, DNA was denatured at $95^{\circ} \mathrm{C}$ for $2 \mathrm{~min}$ and amplified in 35 cycles with denaturation at $95^{\circ} \mathrm{C}$ for $30 \mathrm{~s}$, annealing at $55^{\circ} \mathrm{C}$ for $20 \mathrm{~s}$, and extension at $72^{\circ} \mathrm{C}$ for $30 \mathrm{~s}$. A final extension at $72^{\circ} \mathrm{C}$ for $10 \mathrm{~min}$ completed the PCR. Two paired primers, Cs-1F/Cs-1R-2 and Cs-2F/Cs-5R-2, were identified as optimized wild-type sensitive and G143A mutant-specific probes, respectively, for an allele-specific diagnosis assay (Table 3). For every isolate tested, two PCR reactions allowed discrimination between QoI-sensitive and -resistant isolates, where a 359-bp product using the $\mathrm{Cs}-1 \mathrm{~F} / \mathrm{Cs}-1 \mathrm{R}-2$ primer set combined with no amplification product from the Cs-2F/Cs-5R-2 primer set was indicative of a sensitive strain (Fig. 3A). Likewise, a 207-bp amplicon using the Cs-2F/Cs-5R-2 primer set and no amplification with Cs-1F/Cs-1R-2 indicated a QoI-resistant strain. In no cases were amplicons produced from both primer sets from DNA from a single isolate. The Cs-1F/Cs-1R-2 primer set produced a 359-bp amplicon using $10.0 \mathrm{ng}$ to approximately $2.4 \mathrm{pg}$ of DNA as template in PCR reactions (Fig. 3B). The Cs-2F/Cs5R-2 primer set produced a 207-bp amplicon using $10 \mathrm{ng}$ to approximately $2.4 \mathrm{pg}$ of DNA as template in PCR reactions, with a similar PCR amplification efficiency (Fig. 3b).

Molecular diagnosis of the G143A mutation site to discriminate QoI-resistant and -sensitive isolates using an SNP TaqMan assay. By using an SNP TaqMan assay, it was possible to detect the G143A mutation and to differentiate between isolates sensitive or resistant to QoI fungicides. The SNP could be distinguished by using specific probes in which the nucleotide at the $3^{\prime}$ end is complementary to one allele but forms a mismatch with the second allele.

To confirm that the assay can be used to detect the simultaneous presence of the two alleles, DNA from the wild-type (QoI-sensitive) and mutant (QoI-resistant) isolates were mixed in different proportions. Satisfactory discrimination between the two alleles was possible, and the mutant allele was detected in DNA mixtures where the ratio of DNA from a resistant isolate to that from a susceptible isolate was as low as $3 \%$.

The linearity of the amplification across a range of dilutions was confirmed, and the correlation coefficients for the standard curves of DNAs from sensitive and resistant isolates were 0.999 and 0.997 , respectively (Table 4). The specificity of the assay was tested using DNA from other fungi. Amplification was only detected with DNA extracted from $C$. sojina (data not shown).

The TaqMan assay also was validated by screening 67 C. sojina isolates collected in Arkansas. These isolates were previously tested for resistance to QoI fungicides. The assay was successful in discriminating between QoI-sensitive and QoI-resistant isolates (Fig. 4). Furthermore, the assay was used to screen $114 C$. sojina isolates collected from soybean production fields in Illinois. The assay predicted that $64.03 \%$ of the tested isolates harbored the G143A mutation. This was confirmed by sequencing 87 of the collected isolates (data not shown).

Intron investigation in $C$. sojina. A collection of $C$. sojina isolates was screened for the presence of an intron following codon 143 or at codon 169 of the cytochrome b gene. Isolates with and without the introns were distinguishable by the size of the amplified fragment after separation in agarose gels. The combination of primer pairs used produced amplicons spanning codon 143 and amplicons spanning codon 169. Our results indicate that none of the isolates had an intron directly downstream of codon 143 but all isolates had an intron directly downstream of codon 169 .

\section{Discussion}

Based on our results, the G143A point mutation is responsible for QoI fungicide resistance in C. sojina. Recently, isolates of another important plant pathogen within the genus Cercospora, $C$. beticola, were reported to have the G143A mutation causing QoI resistance in several locations in North America $(6,7,21,33)$ and Europe (5). Among all fungal plant pathogens reported to have resistance to QoI fungicides, the G143A mutation is the most frequently observed point mutation, and pathogens with this mutation have the highest resistance factor compared with other point mutations for QoI resistance (16). This mutation has been reported to occur across several classes of ascomycete fungi as well as oomycetes (17). Because of the high resistance factor associated with the G143A mutation, QoI fungicides will be ineffective in managing frogeye leaf spot caused by isolates that contain the G143A mutation.

An intron directly downstream of codon 143 of the cytochrome b gene was not found in any of the QoI-resistant or -sensitive $C$. sojina isolates. Several plant-pathogenic fungi have been reported to have an intron directly after codon 143 in the cytochrome b gene, which, in the presence of the G143A mutation, leads to a lethal deficiency of cytochrome $b$, thus reducing the likelihood of the G143A mutation building up in the population $(19,32,33)$. Samuel et al. (30) reported that different populations of Botrytis cinerea varied in the presence of the intron but that only isolates without the intron had the G143A point mutation. Although the intron was not detected in our C. sojina isolates, it is possible that some populations of this fungus may possess the intron. Thus, the knowledge of the presence or absence of this intron in populations of $C$. sojina is extremely important to assess the risk of the QoI fungicide resistance in this pathogen.

This research was focused on QoI-resistant $C$. sojina isolates collected from Arkansas, Illinois, and Tennessee. Additional research is underway to determine the geographical distribution of QoI resistance in C. sojina in the United States. The molecular tools described herein may be a more precise, efficient, and less costly method of identifying G143A mutant $C$. sojina isolates than spore germination assays $(40,41)$ and mycelial growth assays (25) conducted in fungicide-amended media, and should aid in the detection of QoIresistant $C$. sojina in new areas. Monitoring $C$. sojina isolates across

Table 4. Slope, efficiencies, correlation coefficients $\left(R^{2}\right)$, and y-intercepts for amplification of serial dilutions of DNA from Cercospora sojina isolates sensitive and resistant to quinone outside inhibitor fungicides using TaqMan single-nucleotide polymorphism assay to detect the G143A mutation

\begin{tabular}{lcccc}
\hline Allele & Slope & Efficiency $(\%)$ & $\boldsymbol{R}^{\mathbf{2}}$ & $\boldsymbol{y}$-intercept \\
\hline Wild-type-sensitive & -3.27 & 102.2 & 0.999 & 26.285 \\
Mutant-resistant & -3.052 & 112.74 & 0.997 & 25.603 \\
\hline
\end{tabular}

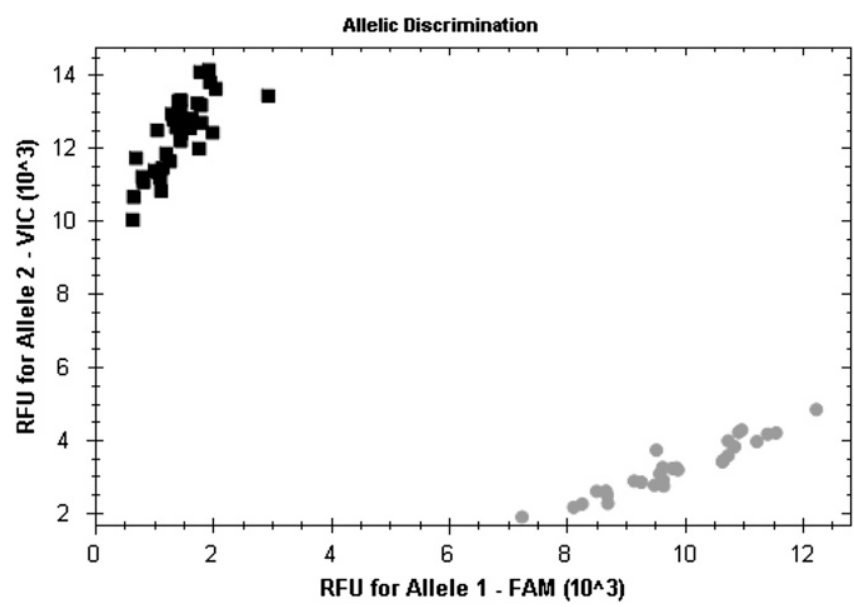

Fig. 4. Allele discrimination plot obtained by using the TaqMan single-nucleotide polymorphism assay to detect the G143A mutation in Cercospora sojina isolates collected in Arkansas. The plot shows clear separation between the signals derived from amplifications of the mutant allele (darker squares) and the wild-type allele (lighter circles). 
multiple states will help provide information about the geographic distribution of QoI-resistant isolates. Because the percentage of fungicide-treated soybean hectares varies across states (34), knowing the geographic distribution of G143A mutant $C$. sojina will help determine any relationships with fungicide use on soybean. In addition, knowing the current G143A mutant $C$. sojina distribution will allow future monitoring to determine the effect of any fungicide resistance mitigation practices.

In light of the high selection pressure and risk of additional areas with QoI-resistant $C$. sojina, frogeye leaf spot management practices should be utilized that reduce additional selection of QoI-resistant isolates. This may require a greater emphasis on using nonchemical management practices such as crop rotation, tillage to bury infested residue, and host resistance. Unfortunately, limitations also may exist with alternative management tactics. By conducting a $C$. sojina survival study in Illinois, Zhang and Bradley (39) reported that a nonhost crop may need to be planted for at least 2 years before overwintering $C$. sojina becomes nonviable. In a state like Illinois, where the majority of crop land is rotated between only corn and soybean, planting corn (a nonhost crop) for $2+$ years between soybean crops to reduce $C$. sojina inoculum may not be economically feasible or biologically sustainable. In addition, Zhang and Bradley (39) reported that burying soybean residue did not affect $C$. sojina survival. Host resistance is an economical way to manage frogeye leaf spot but selection of new races that are virulent against most of the major resistant genes (Rcs genes) has been a recurring problem $(2,23,27,29)$. To date, the $R \operatorname{cs} 3$ gene has been effective against all known races of $C$. sojina in the United States $(13,28)$ but overreliance on this gene could result in the selection of virulent races. Use of alternative fungicide classes could be an additional method of reducing selection of QoI-resistant isolates and controlling frogeye leaf spot. Demethylation inhibitor, methylbenzimidazole carbamate, and organo tin compounds have all shown efficacy against frogeye leaf spot $(1,3,14,15,18)$ but risk of resistance to these fungicide classes also exist. Use of foliar fungicides on field crops such as soybean and corn for reasons other than disease control is becoming common in the major soybean- and corn-producing states $(8,9,12,36)$. The continued practice of applying foliar fungicides for reasons other than disease control likely will apply additional and generally nonwarranted selection pressure on $C$. sojina and other potential fungal pathogen populations, which may warrant continued monitoring of fungal pathogens for resistance to high risk fungicides. Overall, management of frogeye leaf spot and other fungal foliar diseases of soybean likely will become more complex now that QoI-resistant $C$. sojina isolates have been detected across multiple states.

\section{Acknowledgments}

We thank the United States Department of Agriculture-National Institute of Food and Agriculture-Soybean Disease Biotechnology Center Grants Program, the United Soybean Board, and the Illinois Soybean Association for financial support of this research.

\section{Literature Cited}

1. Akem, C. N. 1995. The effect of timing of fungicide applications on control of frogeye leaf spot and grain yield of soybeans. Eur. J. Plant Pathol. 101:183-187.

2. Athow, K. L., Probst, A. H., Kartzman, C. P., and Laviolette, F. A. 1962. A newly identified physiological race of Cercospora sojina on soybean. Phytopathology 52:712-714.

3. Backman, P. A., Rodriguez-Kabana, R., Hammond, J. M., and Thurlow, D. L. 1979. Cultivar, environment, and fungicide effects on foliar disease losses in soybeans. Phytopathology 69:562-564.

4. Bartlett, D. W., Clough, J. M., Godwin, J. R., Hall, A. A., Hamer, M., and ParrDobrzanski, B. 2002. The strobilurin fungicides. Pest Manag. Sci. 58:649-662.

5. Birla, K., Rivera-Varas, V., Secor, G. A., Khan, M. F. R., and Bolton, M. D. 2012. Characterization of cytochrome b from European field isolates of Cercospora beticola with quinone outside inhibitor resistance. Eur. J. Plant Pathol. 134:475-488.

6. Bolton, M. D., Rivera, V., and Secor, G. 2013. Identification of the G143A mutation associated with QoI resistance in Cercospora beticola field isolates from Michigan, United States. Pest Manag. Sci. 69:35-39.

7. Bolton, M. D., Rivera-Varas, V., Secor, G. A., Cattanach, A. W., and Metzger, M. S. 2013. Identification of the G143A mutation in cytochrome b associated with QoI resistance in Cercospora beticola isolates from the Red River Valley. Online publication. Plant Health Prog. 10.1094/PHP-2013-0812-02-RS.
8. Bradley, C. A. 2012. Factors considered when making corn foliar fungicide application decisions in Illinois. Online publication. J. Ext. 50, 3:Article 3RIB7. http://www.joe.org/joe/2012june/rb7.php.

9. Bradley, C. A., and Ames, K. A. 2010. Effect of foliar fungicides on corn with simulated hail damage. Plant Dis. 94:83-86.

10. Bradley, C. A., Wood, A., Zhang, G. R., Murray, J. E., Phillips, D. V., and Ming, R. 2012. Genetic diversity of Cercospora sojina revealed by amplified fragment length polymorphism markers. Can. J. Plant Pathol. 34: 410-416.

11. Cha, R. S., Zarbl, H., Keohavong, P., and Thilly, W. G. 1992. Mismatch amplification mutation assay (MAMA): application to the c-H-ras gene. PCR Methods Appl. 2:14-20.

12. Conley, S. P., Krupke, C., Santini, J., and Shaner, G. 2007. Pest management in Indiana soybean production systems. Online publication. J. Ext. 45, 4: Article 4RIB8. http://www.joe.org/joe/2007august/rb8.php.

13. Cruz, C. D., and Dorrance, A. E. 2009. Characterization and survival of Cercospora sojina in Ohio. Online publication. Plant Health Prog. 10.1094/ PHP-2009-0512-03-RS.

14. Dashiell, K. E., and Akem, C. N. 1991. Yield losses in soybeans from frogeye leaf spot caused by Cercospora sojina. Crop Prot. 10:465-468.

15. Dorrance, A. E., Cruz, C., Mills, D., Bender, R., Koenig, M., LaBarge, G., Leeds, R., Mangione, D., McCluer, G., Ruhl, S., Siegrist, H., Sundermeier, A., Sonnenberg, D., Yost, J., Watters, H., Wilson, G., and Hammond, R. B. 2010. Effect of foliar fungicide and insecticide applications on soybeans in Ohio. Online publication. Plant Health Prog. 10.1094/PHP-2010-0122-01-RS

16. Fisher, N., and Meunier, B. 2008. Molecular basis of resistance to cytochrome bc1 inhibitors. FEMS Yeast Res. 8:183-192.

17. Fungicide Resistance Action Committee. 2013. List of plant pathogenic organisms resistant to disease control agents. Online publication. http://www frac.info/docs/default-source/publications/list-of-resistant-plant-pathogens/listof-resistant-plant-pathogenic-organisms---february-2013.pdf?sfvrsn=4.

18. Galloway, J. 2008. Effective management of soyabean rust and frogeye leaf spot using a mixture of flusilazole and carbendazim. Crop Prot. 27:566571.

19. Grasso, V., Palermo, S., Sierotzki, H., Garibaldi, A., and Gisi, U. 2006 Cytochrome $\mathrm{b}$ gene structure and consequences for resistance to Qo inhibitor fungicides in plant pathogens. Pest Manag. Sci. 62:465-472.

20. Kim, H., Newell, A. D., Cota-Sieckmeyer, R. C., Rupe, J. C., Fakhoury, A. M. and Bluhm, B. H. 2013. Mating-type distribution and genetic diversity of Cercospora sojina populations on soybean from Arkansas: evidence for potential sexual reproduction. Phytopathology 103:1045-1051.

21. Kirk, W. W., Hanson, L. E., Franc, G. D., Stump, W. L., Gachango, E., Clark, G., and Stewart, J. 2012. First report of strobilurin resistance in Cercospora beticola in sugar beet (Beta vulgaris) in Michigan and Nebraska, USA. New Dis. Rep. 26:3.

22. Koenning, S. R., and Wrather, J. A. 2010. Suppression of soybean yield potential in the continental United States by plant diseases from 2006 to 2009. Online publication. Plant Health Prog. 10.1094/PHP-2010-112201-RS.

23. Mian, M. A. R., Missaoui, A. M., Walker, D. R., Phillips, D. V., and Boerma, H. R. 2008. Frogeye leaf spot of soybean: a review and proposed race designations for isolates of Cercospora sojina Hara. Crop Sci. 48:14-24.

24. Nelson, K. A., Motavalli, P. P., Stevens, W. E., Dunn, D., and Meinhardt, C. G. 2010. Soybean response to preplant and foliar-applied potassium chloride with strobilurin fungicides. Agron. J. 102:1657-1663.

25. Olaya, G., Pearsaul, D., Zhang, G., and Bradley, C. 2011. Evaluation of Cercospora sojina isolates sensitive and resistant to azoxystrobin using a mycelial growth inhibition assay. (Abstr.) Phytopathology 101:S132.

26. Phillips, D. V. 1999. Frogeye leaf spot. Pages 20-21 in: Compendium of Soybean Diseases, 4th ed. G. L. Hartman, J. B. Sinclair, and J. C. Rupe, eds. American Phytopathological Society, St. Paul, MN.

27. Phillips, D. V., and Boerma, H. R. 1981. Cercospora sojina race 5: a threat to soybean in the southeastern United States. Phytopathology 71:334-336.

28. Phillips, D. V., and Boerma, H. R. 1982. Two genes for resistance to race 5 of Cercospora sojina in soybeans. Phytopathology 72:764-766.

29. Ross, J. T. 1968. Additional physiological races of Cercospora sojina on soybean in North Carolina. Phytopathology 58:708-709.

30. Samuel, S., Papayiannis, L. C., Leroch, M., Veloukas, T., Hahn, M., and Karaoglanidis, G. S. 2011. Evaluation of the incidence of the G143A mutation and cytb intron presence in the cytochrome bc-1 gene conferring QoI resistance in Botrytis cinerea populations from several hosts. Pest Manag. Sci. 67:1029-1036.

31. Siah, A., Deweer, C., Morand, E., Reignault, P., and Halama, P. 2010 Azoxystrobin resistance of French Mycosphaerella graminicola strains assessed by four in vitro bioassays and by screening of G143A substitution. Crop Prot. 29:737-743.

32. Sierotzki, H., Frey, R., Wullschleger, J., Palermo, S., Karlin, S., Godwin, J., and Gisi, U. 2007. Cytochrome b gene sequence and structure of Pyrenophora teres and $P$. tritici-repentis and implications for QoI resistance. Pest Manag. Sci. 63: 225-233.

33. Trueman, C. L., Hanson, L. E., Rosenzweig, N., Jiang, Q. W., and Kirk, W. W. 2013. First report of QoI insensitive Cercospora beticola on sugar beet in Ontario, Canada. Plant Dis. 97:1255. 
34. United States Department of Agriculture-National Agricultural Statistics Service. 2013. 2012 Agricultural Chemical Use Survey-Soybeans. Online publication. http://www.nass.usda.gov/Quick_Stats/

35. Vallieres, C., Trouillard, M., Dujardin, G., and Meunier, B. 2011. Deleterious effect of the Qo inhibitor compound resistance-conferring mutation G143A in the intron-containing cytochrome $\mathrm{b}$ gene and mechanisms for bypassing it. Appl. Environ. Microbiol. 77:2088-2093.

36. Wise, K., and Mueller, D. 2011. Are fungicides no longer just for fungi? An analysis of foliar fungicide use in corn. Online publication. APSnet Features. 10.1094/APSnetFeature-2011-0531.

37. Wrather, J. A., and Koenning, S. R. 2009. Effects of diseases on soybean yields in the United States 1996 to 2007. Online publication. Plant Health Prog. 10.1094/PHP-2009-0401-01-RS.
38. Wrather, A., Shannon, G., Balardin, R., Carregal, L., Escobar, R., Gupta, G. K., Ma, Z., Morel, W., Ploper, D., and Tenuta, A. 2010. Effect of diseases on soybean yield in the top eight producing countries in 2006. Online publication. Plant Health Prog. 10.1094/PHP-2010-0125-01-RS.

39. Zhang, G., and Bradley, C. A. 2014. Survival of Cercospora sojina on soybean leaf debris in Illinois. Plant Health Prog. 10.1094/PHP-RS-140005

40. Zhang, G. R., Newman, M. A., and Bradley, C. A. 2012. First report of the soybean frogeye leaf spot fungus (Cercospora sojina) resistant to quinone outside inhibitor fungicides in North America. Plant Dis. 96:767.

41. Zhang, G., Pedersen, D. K., Phillips, D. V., and Bradley, C. A. 2012 Sensitivity of Cercospora sojina isolates to quinone outside inhibitor fungicides. Crop Prot. 40:63-68. 